\title{
The behaviour of aluminum alloy 1050 sheet subjected to impact and perforation process: Experimental and numerical approaches
}

\author{
Amine Bendarma ${ }^{(a)}$, Salwa EL Garouge ${ }^{(a)}$, Hajar Akhzouz ${ }^{(a)}$, Said Kardellass ${ }^{(b)}$, Salim \\ Bouslikhane $^{(\mathrm{a})}$, Hassan ELMinor ${ }^{(\mathrm{c})}$ \\ ${ }^{a}$ Laboratoire d'Innovation Durable et de Recherche Appliquée (L.I.D.R.A), Universiapolis, Bab Al Madina, Qr Tilila, Agadir, Morocco \\ ${ }^{b}$ Universiapolis Université Mohammed V de Rabat, École Nationale Supérieure d'Arts et Métiers de Rabat (Ex-ENSET), Avenue des Forces \\ Armées Royales, 10100 Rabat, Morocco \\ ${ }^{c}$ Equipe de recherche Matériaux, Mécanique et Génie Civil, ENSA Agadir, Ibn Zohr University, Morocco
}

\begin{abstract}
The mechanical behavior of aluminum alloy under impact loading using different configurations is described. Perforation tests are referred in this work at wide ranges of specimen using several projectile shapes to analyse their effect on the ballistic curve $V_{R}-V_{0}$ (conical, hemispherical and blunt), with a diameter of 6.mm. A wide range of impact velocities from 40 to $100 \mathrm{~m} / \mathrm{s}$ has been used. Experimental and numerical analysis have been carried out to predict the mechanical behaviour of the studied aluminium alloy. This analysis has been done using a high-pressure gas gun. Specimens were prepared from standard $1.0 \mathrm{~mm}$ and $1.5 \mathrm{~mm}$ thick aluminum sheets with $13 \times 13 \mathrm{~cm}$ plates. The resistance and the energy absorbed by the aluminum sheets under dynamic load were obtained by measuring the initial and residual velocities of the projectiles. The experimental and numerical results are presented and compared in terms of ballistic curve $V_{R}-V_{0}$, a good correlation was observed.
\end{abstract}

Keywords: Gas gun; experimental technique; Aluminum alloy; mechanical properties; Ballistic behavior; Experiment; Numerical simulation.

\section{Introduction}

The studied material in this work is the Aluminum alloy 1050 is frequently used in sheet metal work in different industries, this alloy cannot be heat-treated. It is commonly used in heat transfer applications for the automotive and HVAC industries, as well as in the electrical industry. Alloy 1050 has good corrosion resistance and superior thermal conductivity than other alloys. (The most economical conductive in the 1000 alloy series). [1]

Table 1. Chemical compositions and mechanical properties of aluminum alloys. [1]

\begin{tabular}{|c|c|c|c|c|c|c|c|c|c|c|c|}
\hline \multicolumn{8}{|c|}{ Chemical composition in \% } & \multicolumn{4}{|c|}{ Mechanical proprieties } \\
\hline $\mathrm{Fe}$ & $\mathrm{Si}$ & $\mathrm{Zn}$ & $\mathrm{Mg}$ & $\mathrm{Ti}$ & $\mathrm{Mn}$ & $\mathrm{Cu}$ & $\mathrm{Al}$ & $\begin{array}{c}\text { Proof } \\
\text { Stress(MPa) }\end{array}$ & $\begin{array}{l}\text { Tensile Strength } \\
\text { (MPa) }\end{array}$ & $\begin{array}{c}\text { Hardness } \\
\text { Brinell }\end{array}$ & $\begin{array}{c}\text { Elongation A } \\
(\%)\end{array}$ \\
\hline 0.40 & 0.25 & 0.07 & 0.005 & 0.05 & 0.05 & 0.05 & $\mathrm{Bal}$ & 85 & $105-145$ & 34 & 12 \\
\hline
\end{tabular}

A representative methodology has been adopted to carry out the perforation tests and to deduce the ballistic behavior of the AL 1050 aluminum alloy [2, 3]. The mechanical behavior of aluminum alloy under impact loading using different parameters has been analyzed at wide ranges of impact velocities ( 40 to $120 \mathrm{~m} / \mathrm{s}$ ) using three projectile shapes (conical, hemispherical and blunt) with $6 \mathrm{~mm}$ of diameter, the ballistic and absorbed energy results has been presented and discussed.

* Amine Bendarma. Tel.:+212-; 0661098872

E-mail address: b.amine@e-polytechnique.ma

Theoretical approaches to penetration testing have been of interest to many authors. As an example, Alavi et al [4] investigated the effects of multi-layered aluminum targets on the penetration of a hemispherical-nosed projectile using a one stage gas gun, to reveal a higher ballistic limiting velocity for single-layered targets compared to multi-layered targets and several failure modes.

Besides, the effect of the projectile cone angle on the formation of necks and cracks during perforation of ductile materials has been studied by Atkins et al [5] to highlight the trend of decreasing number of cracks proportionally to the increase of the cone angle. In addition, an analytical model has been developed to quantify the necks and the radial cracks occurring during the perforation of ductile materials by conical or round-ended projectiles. 
The reviews by Borvik et al [6], Kpenyigba et al [7], Rusinek et al [8] and Backman et al [9] explored the target failure mechanisms and the notion of a phase diagram; separating the perforation domain from the ricochet domain. In this context, the authors reported a significant impact of the projectile nose shape on the energy curves and on the failure mode of the plate during the penetration process. As well, the use of the Johnson-Cook (JC) constitutive model is widespread due to the several parameters taken into consideration during the calculations, including the effects of strain rates and temperature parameters [10]. Likewise, the ballistic behavior of materials is related to several factors, including shapes, projectile mass, and plate thickness, and therefore, the complexity of interpretation regarding the influence of these parameters on the results is undeniable [7]. Recent studies has been proposed in order to investigate the ballistic performance of aluminum plates under impact of projectile through experimental and numerical approaches [11.12]. Bendarma et al [13] investigated the Aluminum AW5005 at wide range of strain rates and temperature, a gas gun equipped by a thermal chamber has been used, the temperatures considered during this analysis are room, 60,100 and $300{ }^{\circ} \mathrm{C}$. they observed that the temperature has an influence on the ballistic curves as well as the energy absorbed during the impact and the perforation process. However, the same material has been used in dynamic compression tests [14] using the split hopkinson pressure bar system at high strain rates and temperatures. They found that the temperature influences in a remarkable way the behavior of the material; in addition, a friction analysis with different coefficients between the bars and the specimen during the compression test was made.

\section{Experimental research methodology for perforation}

The behavior of Aluminum sheets under impact loading has been described in this section. The yield stress determined through quasi-static tensile tests is, $\sigma_{y}=145 \mathrm{MPa}$ [1]. In the other hands, in the next sequence of the experimental tests is described. During experimental tests, a rigid projectile has impacted the Aluminum 1050 sheets. The mechanical part of the experimental setup is shown in Fig. 1. The projectile is launched using a pneumatic gas gun; it accelerates in the tube $\mathrm{C}$ to reach a certain velocity namely initial impact velocity $\mathrm{V}_{0}$. Then, the projectile impacts the aluminum sheet with a partial or complete perforation depending on the amount of kinetic energy delivered to the tested material. $[15,16]$
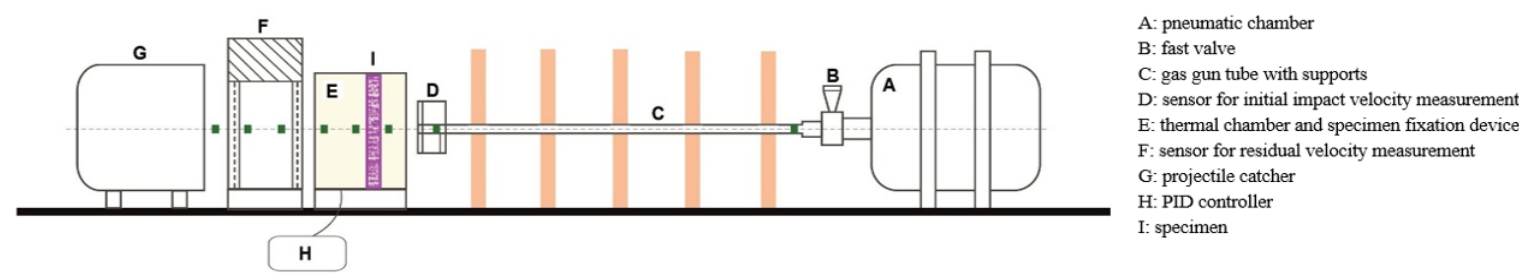

Fig. 1. Experimental device presentation [15].

The dimensions of the specimens used during experiments are $100 \times 100 \mathrm{~mm} 2$, the thickness used in this work is $1,1.5 \mathrm{~mm}$ and it is fixed on a rigid support to reduce sliding effect during the perforation test. A varied intervals of initial impact velocities was considered to describe the ballistic and the absorbed energy curve of the Aluminum 1050 alloy sheet. $[13,15,16]$

In this work, several projectile shapes (Fig. 2) has been used to analyze their effect on the ballistic curve $V_{R}-V_{0}$ $[13,15,16]$.The mass of the projectile is assumed to be constant $m_{p}=10 \mathrm{~g},(6 \mathrm{~mm}$ diameter $)$ respectively, using the same material and different lengths. The projectile was assumed rigid during the perforation tests [17]. The ballistic properties of the material and the modes of failure as a function of the shape of the projectiles (blunt, hemispherical and conical) were studied.
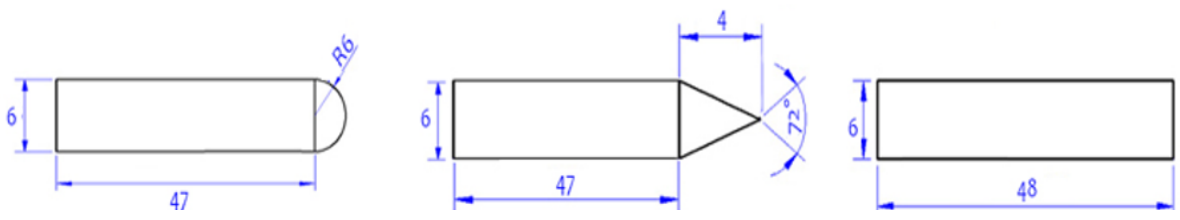

Fig. 2. Projectile's shape used during experiment [17] 


\section{Experimental results}

The results in terms of ballistic curve $V_{R}-V_{0}$ are presented in Fig. 3. The contact between the aluminum sheet and the projectile is not lubricated, $(\mu>0)$.It is observed that there is an increase of the ballistic limit $V_{B}$ for a hemispherical shape projectile in comparison with blunt or conical shapes.
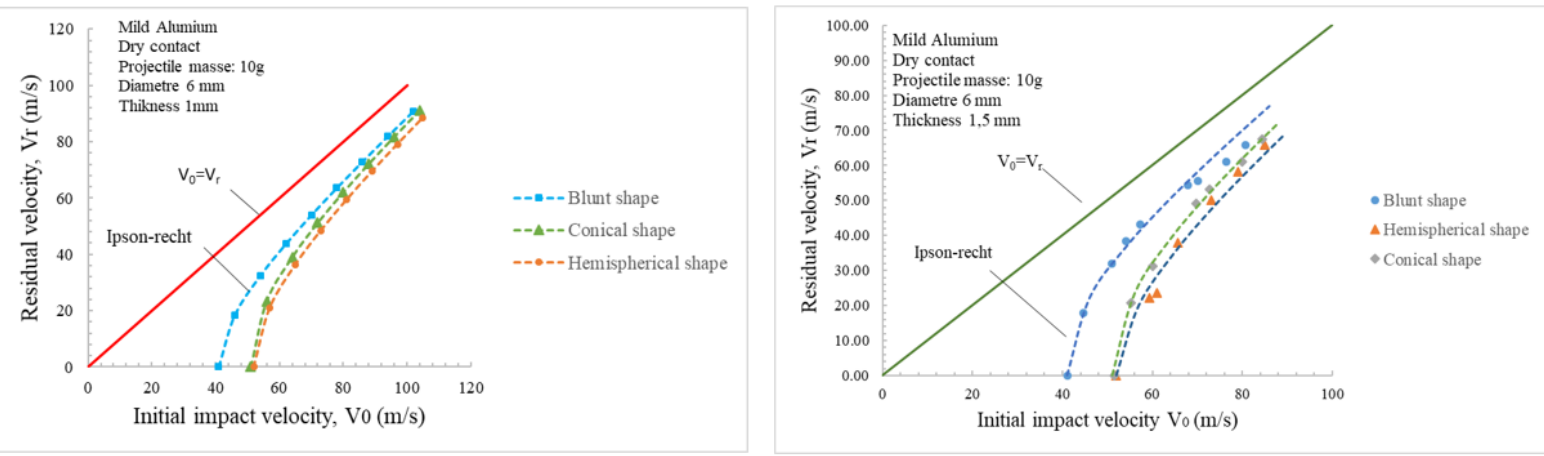

Fig. 3. Experimental ballistic curve depending on the shape of the projectile, diameter and thickness $t 0=1$ and $1.5 \mathrm{~mm}$

When using a blunt or conical projectile, the failure mode is entirely dissimilar. This point is discussed in details in Jankowiak et al [17,19]. Ballistic curves in general, Fig. 3, can be established using the relation proposed by Recht et al. [18], Eq. (1).

$$
V_{R}=\left(V_{0}{ }^{\kappa}-V_{B}{ }^{1}\right)^{1 / \kappa}
$$

where $\mathbf{V}_{\mathbf{0}}$ is the initial velocity and $\mathbf{V}_{\mathbf{B}}$ is the ballistic velocity and $\boldsymbol{k}$ is the ballistic curve shape parameter. Using the above equation, the constants $V_{\mathrm{B}}$ and $\boldsymbol{k}$ are presented in the bales below:

Table 2. The ballistic limit velocities $\mathrm{V}_{\mathrm{B}}$ and the fitting parameter $\boldsymbol{k}$ for $1 \mathrm{~mm}$ thickness plate of AL 1050 using different projectile shapes of 6 mm diameter.

\begin{tabular}{lccc}
\hline Projectile type & Plate thickness & $\mathbf{V}_{\mathbf{B}}(\mathbf{m} / \mathbf{s})$ & $\boldsymbol{k}$ \\
\hline Conical projectile & $1 \mathrm{~mm}$ & 49 & 2.02 \\
Blunt projectile & $1 \mathrm{~mm}$ & 41 & 1.82 \\
Hemispherical projectile & $1 \mathrm{~mm}$ & 50 & 1.85 \\
\hline
\end{tabular}

Table 3. The ballistic limit velocities $\mathrm{V}_{\mathrm{B}}$ and the fitting parameter $\boldsymbol{k}$ for $1.5 \mathrm{~mm}$ thickness plate of AL 1050 using different projectile shapes of 6 mm diameter.

\begin{tabular}{cccc}
\hline Projectile type & Plate thickness & $\mathbf{V}_{\mathbf{B}}(\mathbf{m} / \mathbf{s})$ & $\boldsymbol{k}$ \\
\hline Conical projectile & $1.5 \mathrm{~mm}$ & 51 & 1.80 \\
Blunt projectile & $1.5 \mathrm{~mm}$ & 41 & 2.10 \\
Hemispherical projectile & $1.5 \mathrm{~mm}$ & 52 & 2.02 \\
\hline
\end{tabular}

The energy absorbed by the plate $\boldsymbol{E} \boldsymbol{d}$ can be calculated using the following equation [18], Eq. (2):

$$
E_{d}=\frac{m_{P}}{2}\left(V_{0}^{2}-V_{R}^{2}\right)
$$

The difference of the initial and residual kinetic energy can be calculated using the experimental data for different projectile shapes, see Fig. 4. The energy absorbed by the plate $\boldsymbol{E} \boldsymbol{d}$ (Eq. 2) before failure is nearly the same using a blunt or a conical projectile is lesser than that obtained with a hemispherical projectile. 

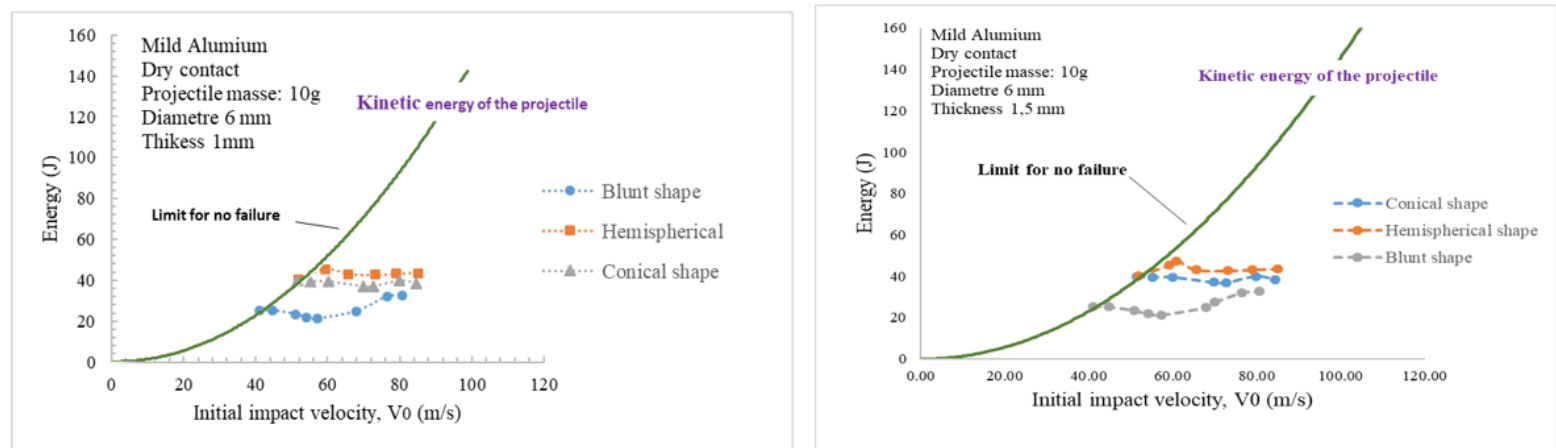

Fig. 4. Energy absorbed by the plate as a function of the shape of the projectile and the initial impact velocity.

The energy dissipation in AL 1050 aluminum alloy sheets is strictly related to the target thickness (1 and $1.5 \mathrm{~mm})$. This mean that the plastic flow process is most important when using a hemispherical shape shell.

However, at a high impact velocities, up to $100 \mathrm{~m} / \mathrm{s}$, the energy is less dependent to the shape of the projectile, compared to values close to the ballistic limit $\mathrm{V}_{\mathrm{B}}$.

\section{Numerical simulation of the perforation process}

To carry out the numerical approach of the perforation process, a parametric study of the aluminium alloy AL1050 was carried out, using the Johnson-Cook's constitutive law as a model.

The studied constitutive relation (JC) [10] is described by several authors and is implemented in commercial finite element codes such as ABAQUS.

The explicit formulation of the JC thermoviscoplastic model is defined as follows:

$$
\sigma=\left(A+B \varepsilon^{n}\right)\left[1+C \cdot \operatorname{Ln} \frac{\dot{\varepsilon}}{\varepsilon_{0}}\right]\left[1-\left(T^{*}\right)^{m}\right]
$$

where A is the yield stress, B is the material constant, $\mathrm{n}$ is the coefficient of hardening, $\mathrm{C}$ is the coefficient of sensitivity to strain rate and $\mathrm{m}$ is the sensitivity to temperature. To define the thermal softening of the studied material during a dynamic load. The non-dimensional temperature $T^{*}$ for the temperature in range between $T_{0}$ and $T_{m}$ is defined in the following form:

$$
T^{*}=\frac{T-T_{0}}{T_{m}-T_{0}}
$$

\subsection{Numerical results}

The optimal mesh was obtained by using a convergence method (stability of the results with no mesh dependency). The mesh is densest in the projectile-plate contact area, the plate thickness in this area is $1.0 \mathrm{~mm}$, and the velocity is set to the present fields with the impact velocity range of $40-120 \mathrm{~m} / \mathrm{s}$ as conceded in the experiment. This model contains 5184 elements in the central impact part and 6381 with the same element size $(0.4 \times 0.4 \mathrm{~mm})$. Ballistic curves are reported and compared with the experimental results. The inner zone of the model allows to precisely initiate the crack propagation process. 


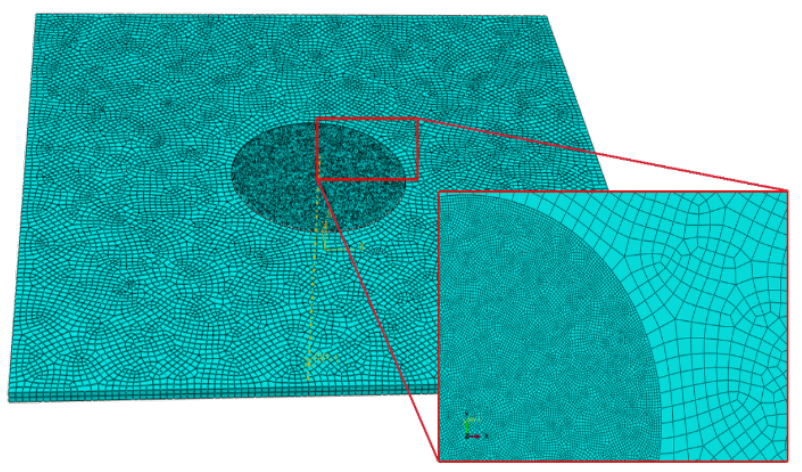

Fig. 5 Numerical model used during numerical simulations (mesh density distribution).

To get a complete validation of the numerical model, the ballistic curves are reported and compared with the experimental results Fig.7. A good covenant is observed between numerical simulations and experiments.
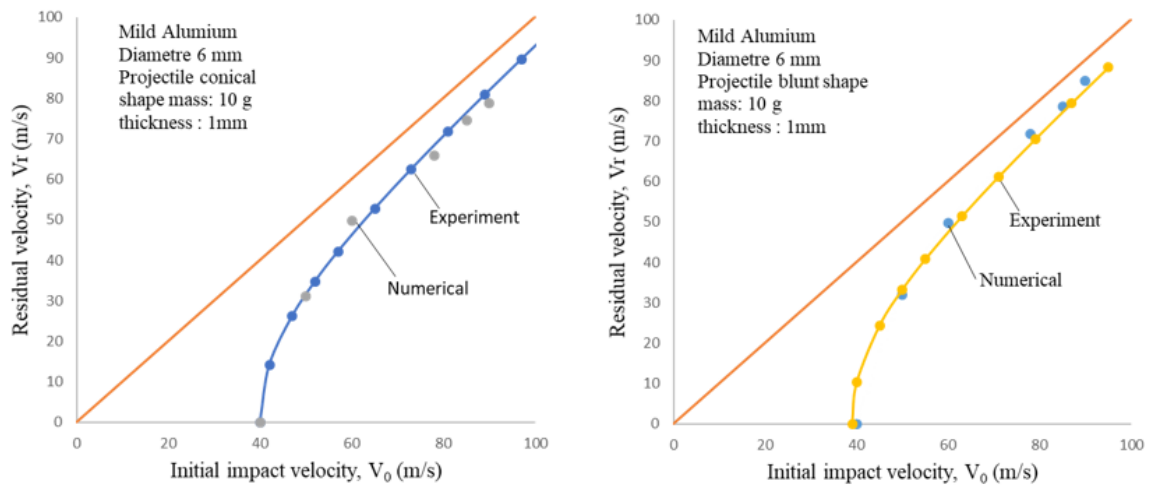

Fig. 6 Numerical results in comparison with experiment

\section{Conclusion}

The paper describes the mechanical behavior of Aluminum alloy sheets under impact loading. The work is focused on perforation tests carried out at wide range of velocity. As discussed in this work the ballistic properties of the material is dependent on the projectile's shape (conical, blunt and hemispherical) with $6 \mathrm{~mm}$ of diameters. A specific analysis has shown that the number of petals that forms after perforation of the plate decreases with the conical angle of the projectile, a typical failure behaviour was perceived and relay on both the impact velocity and the projectiles shape. The experimental investigations were extended by means of numerical simulations using the general software Abaqus / Explicit. The constitutive phenomenological relation has been verified together with a failure criterion. Finally, a good correlation is obtained between the numerical and experimental results. And the failure mode suitable for numerical simulation curves that fits well with the experiment.

\section{Acknowledgements}

This work was financed and supported by the International University of Agadir (Universiapolis). Thanks to $\mathrm{Mr}$ Abdellah Souleimani for his support and help. The system has been developed in agreement between IPPT, Universiapolis Agadir and Lorraine University; patent no. 41383 Kingdom of Morocco (2017).

\section{References}

[1] S. Golru, M. Sharifi, M. B. Attar, and B. Ramezanzadeh. "Effects of surface treatment of aluminium alloy 1050 on the adhesion and anticorrosion properties of the epoxy coating." Applied Surface Science 345 (2015): 360-368.

[2] T. Borvik, M. Langseth, O.S. Hoperstad and K.A. Malo. "Ballistic penetration of steel plates. International journal of impact engineering", 22(9-10) . (1999), 855-886. 
[3] A.Rusinek, J. A. Rodríguez-Martínez, R. Zaera, J. R. Klepaczko, , A. Arias, \& C. Sauvelet. "Experimental and numerical study on the perforation process of mild steel sheets subjected to perpendicular impact by hemispherical projectiles." International Journal of Impact Engineering 36.4 (2009): 565-587.

[4] Nia, A. Alavi, G. R. Hoseini. "Experimental study of perforation of multi-layered targets by hemispherical-nosed projectiles." Materials \& Design 32.2 (2011): 1057-1065.

[5] A. G.Atkins, J. H. Liu. "Necking and radial cracking around perforations in thin sheets at normal incidence." International journal of impact engineering 21.7 (1998): 521-539.

[6] T. Borvik, M. Langseth, O.S. Hoperstad and K.A. Malo, "Perforation of $12 \mathrm{~mm}$ thick steel plates by $20 \mathrm{~mm}$ diameter projectiles with flat, hemispherical and conical noses part I: experimental study". International journal of Impact Engineering, 27, 19-35, 2002.

[7] K. M .Kpenyigba, T. Jankowiak, A. Rusinek, R. Pesci. "Influence of projectile shape on dynamic behavior of steel sheet subjected to impact and perforation." Thin-Walled Structures 65 (2013): 93-104.

[8] A. Rusinek, J. A .Rodríguez-Martínez, A.Arias, J. R .Klepaczko, J.López-Puente. "Influence of conical projectile diameter on perpendicular impact of thin steel plate." Engineering Fracture Mechanics 75.10 (2008): 2946-2967.

[9] M.E. Backman, W. Goldsmith, "The mechanics of penetration of projectiles into targets", International Journal of Engineering Science, 16, 1, 1-99, 1987.

[10] R. Johnson, R. Gordon, H. Cook .William. "Fracture characteristics of three metals subjected to various strains, strain rates, temperatures and pressures." Engineering fracture mechanics 21.1 (1985): 31-48.

[11] A. Bendarma, A., H. Gourgue, H., T. Jankowiak, T., A. Rusinek, A., S. Kardellass, \& M. Klosak. ."Perforation tests of composite structure specimens at wide range of temperatures and strain rates-experimental analysis". Materials Today: Proceedings. (2019).

[12] Bendarma, A., Rusinek, A., Jankowiak, T., Lodygowski, T., \& Jia, B. (2021). "Experimental analysis of the aluminum alloy sheet subjected to impact and perforation process". Materials Today: Proceedings, 36, 88-93.

[13] A. Bendarma, T. Jankowiak, A.Rusinek, T. Lodygowski, M. Klosak. "Perforation Tests of Aluminum Alloy Specimens for a Wide Range of Temperatures Using High-Performance Thermal Chamber-Experimental and Numerical Analysis." IOP Conference Series: Materials Science and Engineering. Vol. 491. No. 1. IOP Publishing, 2019.

[14] Bendarma, A., Jankowiak, T., Rusinek, A., Lodygowski, T., Jia, B., Miguélez, M. H., \& Klosak, M. (2020). "Dynamic Behavior of Aluminum Alloy Aw 5005 Undergoing Interfacial Friction and Specimen Configuration in Split Hopkinson Pressure Bar System at High Strain Rates and Temperatures". Materials, 13(20), 4614.

[15] M. Klosak, A. Rusinek, A. Bendarma. "Experimental study of brass properties through perforation tests using a thermal chamber for elevated temperatures." Latin American Journal of Solids and Structures 15.10 (2018).

[16] A. Bendarma, T. Jankowiak, A.Rusinek, T. Lodygowski, M. Klosak . "Experimental and numerical analysis of the aluminum alloy AW5005 behavior subjected to tension and perforation under dynamic loading." Journal of Theoretical and Applied Mechanics 55.4 (2017): 1219-1233.

[17] T. Jankowiak, A. Rusinek, K.M. Kpenyigba, R. Pesci. "Ballistic behavior of steel sheet subjected to impact and perforation." Steel and Composite Structures 16.6 (2013): 595-609.

[18] Recht, RoF, and T. W. Ipson. "Ballistic perforation dynamics." Journal of Applied Mechanics 30.3 (1963): 384-390.

[19] Jia, B., Rusinek, A., Pesci, R., Bernier, R., Bahi, S., Bendarma, A., \& Wood, P. (2021). "Simple shear behavior and constitutive modeling of 304 stainless steel over a wide range of strain rates and temperatures". International Journal of Impact Engineering, 154, 103896. 